\title{
A Pattern of Age-related Macular Degeneration
}

\author{
Pokharel S, ${ }^{1}$ Malla OK, ${ }^{1}$ Pradhananga CL, ${ }^{1}$ Joshi SN ${ }^{2}$ \\ 'Department of Ophthalmology, Kathmandu Medical College, ${ }^{2}$ Department of Ophthalmology, Institute of Medicine, Maharaj- \\ gunj, Kathmandu, Nepal.
}

\section{ABSTRACT}

Introduction: Age related macular degeneration is a disorder of the macula most often clinically apparent affecting central vision and is one of the leading causes of blindness in the population above 50 years. The aim of this study is to determine clinical profile of AMD in Nepalese presenting to a Teaching Hospital in Kathmandu.

Methods: It was a hospital-based cross-sectional study. The subjects included in the study were those presenting to the Ophthalmology department of Kathmandu Medical College Teaching Hospital from July 2007- Dec 2007.The total number of individuals included in the study were 402 and total number of eyes were 804 .

Results: AMD was observed in 5.2\% out of 402 subjects of 40 years and above age group with prevalence increasing with age. The prevalence of AMD was $0.7 \%$ within $40-50$ years of age-group individuals increasing to $2.6 \%$ in $51-60$ years, $6.5 \%$ in $61-70$ years and to $19.3 \%$ among subjects above 71 years. This study revealed that the prevalence of AMD in females was higher with female preponderance in ratio of 2.5:1. 52.5\% AMD subjects in our study had visual impairment with 6/24$6 / 60$ vision and $15 \%$ had vision $<3 / 60$-PL. Our study revealed statistically significant increased risk for AMD with aging $(p=0.00)$. Increased risk was observed in female gender and diabetics though the Odds ratio (OR) was statistically insignificant $(\mathrm{p}=>0.01)$.

Conclusions: Prevalence of AMD in Nepalese presenting to Kathmandu Medical College Teaching Hospital was $5 \%$ with female preponderance in ratio of 2.5:1. Aging showed statistically significant increased risk for AMD development in this study.

Key Words: Age-related macular degeneration, blindness, Nepalese, prevalence

\section{INTRODUCTION}

AMD is the leading cause of blindness in patients above the age of 50 years in developed countries. ${ }^{1}$ It accounts for $13 \%$ of all cases of legal blindness in the USA with more than 200000 new cases reported each year. ${ }^{1}$ The pathogenesis of this disorder is poorly understood. It is multifactorial, involving genetic factors, adverse effects caused by tobacco smoking, and an association with atherosclerosis..$^{2-4}$

The age related eye disease study recommends the use of multivitamins or antioxidants to reduce risk of advanced AMD. ${ }^{5}$ Age is the most important risk factor for the development of the disease. Approximately $10 \%$ of patients aged $66-74$ years will have AMD. The prevalence increases to $30 \%$ in the age group $75-85$

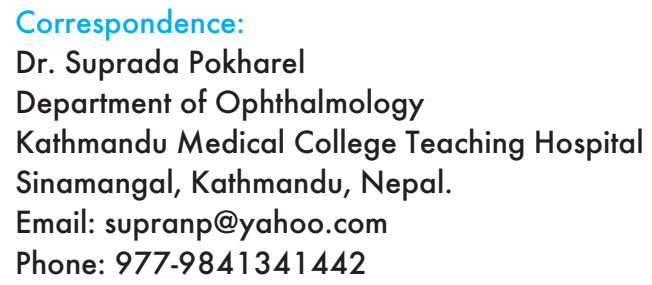


Pokharel et al. A Pattern of Age-related Macular Degeneration

years. ${ }^{1-8}$ This study aims to find out the pattern of AMD in our context.

\section{METHODS}

A hospital based cross-sectional study in the department of Kathmandu Medical College Teaching Hospital from July, 2007- December, 2007. Ethical approval and patient consent was taken. The sampling method was randomized sampling with the participants age 40 years and above. Informed verbal consent was taken from all the study subjects. Detailed history of all cases was taken. All selected individuals were subjected to systemic examination and detailed ocular examination with dilated pupils. The individuals 40 years and above with no history of optic nerve diseases, glaucoma, active intraocular inflammation, corneal scarring, and corneal diseases were included. But age less than 40 years, cases who refused to be a part of the study and with history of optic nerve diseases, glaucoma, active intraocular inflammation, corneal scarring, and corneal diseases were excluded.

Diagnostic criteria for AMD were presence of hard or amorphous or calcified drusens in the macula, small or large with hyperpigmentation or hypopigmentation of retinal pigment epithelium with loss of vision $\geq 6 / 12$ with Amsler grid defect or Amsler grid blurring vision; Presence of choroidal neovascularization and macular exudates; Presence of macular disciform scarring; Cases with AMD or drusen were included in the study even with presence of the condition in one eye only; Cases with no clear view of fundus in one eye but presence of the above mentioned conditions in the other eye were also included for analysis as presence of AMD or drusen.

Statistical analysis of study subjects was done using statistical package for social sciences (SPSS) version 13 for windows. Chi-square test, correlation and logistic regression tests were analyzed.

\section{RESULTS}

The numbers of subjects in the age group $40-50$ years were $139(34.6 \%)$. There were $114(28.4 \%)$ in agegroup $51-60$ years, $92(22.9 \%)$ in $61-70$ years and 57 $(14.2 \%)$ in age-group $>71$ years. The oldest case was 89 years old. There were 229 (57\%) female subjects and $173(43 \%)$ males.

Out of 804 eyes in this study, $5 \%$ had AMD. Out of 402 right eyes, AMD was found in $4.7 \%$ and out of 402 left eyes it was present in $5.2 \%$ (Table 1 ).
The drusen formation was observed in $18.5 \%$ in 804 eyes. Out of 402 individuals, drusen were found in $10 \%$ of the individuals in the age group 40-50 years which increased to $36.3 \%$ in $60-70$ years.

Out of 40 AMD eyes, $5 \%$ had exudative AMD and $95 \%$ had atrophic AMD. Among them $4.8 \%$ AMD were in age group 40-50 years out of 21 AMD cases (Table 2).

Table 2. Age distribution

\begin{tabular}{lll}
\hline Age-group & $\begin{array}{l}\text { Right eyes AMD } \\
\text { No }(\%)\end{array}$ & $\begin{array}{l}\text { Left eyes } \\
\text { AMD No (\%) }\end{array}$ \\
\hline $40-50$ & $1(5.3)$ & $1(4.8)$ \\
$51-60$ & $2(10.5)$ & $3(14.3)$ \\
$61-70$ & $5(26.3)$ & $6(28.6)$ \\
$>71$ & $11(57.9)$ & $11(52.4)$ \\
Total & $19(100.0)$ & $\mathbf{2 1 ( 1 0 0 . 0 )}$ \\
\hline
\end{tabular}

Within total $40-50$ years of age-group individuals, $0.7 \%$ had AMD increasing to $2.6 \%$ in $51-60$ years, $6.5 \%$ in 61-70 years and to $19.3 \%$ among subjects above 71 years. Thus the prevalence of AMD was found to be gradually increasing with age.

Out of 21 AMD cases, $76.2 \%$ were females in our study and $23.8 \%$ males (Table 3 ). Within female gender, $7 \%$ had AMD while only $2.9 \%$ of total male study individuals had AMD.

Table 3. Sex distribution

\begin{tabular}{lll}
\hline Sex & Right eyes AMD No (\%) & Left eyes AMD No (\%) \\
\hline Female & $15(78.9)$ & $16(76.2)$ \\
Male & $4(21.1)$ & $5(23.8)$ \\
Total & $19(100.0)$ & $21(100.0)$ \\
\hline
\end{tabular}

Our study reveals prevalence differences in male and female gender with higher prevalence in females. The prevalence of AMD was found to be 2.5 times higher in females than in males (OR: 1.122 with $95 \%$ confidence interval lower 0.098; upper 1.081; $p=0.068$ ). However this female-male distribution was found to be statistically insignificant.

In our study, $52.5 \%$ had visual impairment with vision 6/24- 6/60 while $15 \%$ had vision <3/60- PL (perception of light) out of 40 AMD eyes (Table 4).

Table 1. Distribution of AMD

\begin{tabular}{lcccc}
\hline AMD & Yes (\%) & No (\%) & No view (\%) & Total (\%) \\
\hline Right eyes AMD No (\%) & $19(4.7)$ & $381(94.8)$ & $2(0.5)$ & $402(100)$ \\
Left eyes AMD No (\%) & $21(5.2)$ & $378(94)$ & $3(0.7)$ & $402(100)$ \\
Total & $40(5)$ & $759(94.4)$ & $5(0.6)$ & $804(100)$ \\
\hline
\end{tabular}


Pokharel et al. A Pattern of Age-related Macular Degeneration

Table 4. Visual acuity

\begin{tabular}{lll}
\hline Visual acuity in AMD & Right eyes No \% & Left eyes No \% \\
\hline $6 / 12-6 / 18$ & $6(31.6)$ & $6(28.6)$ \\
$6 / 24-6 / 60$ & $9(47.4)$ & $12(57.1)$ \\
$5 / 60-3 / 60$ & $1(5.3)$ & $0(0.0)$ \\
$<3 / 60-P L$ & $3(15.8)$ & $3(14.3)$ \\
NPL & $0(0.0)$ & $0(0.0)$ \\
Total & $19(100.0)$ & $\mathbf{2 1}(100.0)$ \\
\hline
\end{tabular}

Out of 21 AMD cases, 3 (14.5\%) were hypertensive in our study. There were $4.8 \%$ (only one case) diabetics. Total $7(33.3 \%)$ were smokers in this study. Total 5 $(23.8 \%)$ were cases taking alcohol in our AMD study.

The study showed increased risk for AMD with aging which was statistically significant. The OR for aging revealed 2.221 times greater risk for development of AMD in age group $>71$ years when compared with $\leq 70$ years age-group.

Increased risk was observed in female gender and diabetics though the OR was statistically insignificant. There was no association observed for AMD with alcohol intake, hypertension, smoking, and vegetarian status in our study $(p=>0.01)$.

\section{DISCUSSION}

The prevalence of AMD varies from $1.2 \%$ to $29.3 \%$ world-wide. Three population based studies-the Beaver Dam Eye Study, Blue Mountain Eye Study and the Rotterdam Study report the prevalence rates to be $1.7 \%$ in US, $1.4 \%$ in Australia and $1.2 \%$ in Netherlands respectively. ${ }^{8-10}$ The prevalence rate observed in South India was $1.1 \%$ and $17.4 \%$ in Africa. ${ }^{11-12}$ Another study from North India reports the prevalence rate to be $4.7 \% .{ }^{13}$ In China the incidence in an observational series was $5.88 \% .{ }^{14}$ The overall AMD prevalence rate in right eyes was 4.1 percent in the Funagata study in Japan. ${ }^{15}$

The prevalence of AMD observed in our study was $5 \%$ out of 804 eyes. AMD prevalence was $0.7 \%$ in $40-50$ years of age-group individuals, increasing to $2.6 \%$ in
51-60 years, $6.5 \%$ in $61-70$ years and to $19.3 \%$ among subjects above 71 years. There is no population-based AMD study carried out in our country for comparison. However, the prevalence of AMD observed in various retina clinics in Nepal was found to range from $4 \%$ $8.4 \%$.

In US, the prevalence of AMD increased dramatically with age, with more than $15 \%$ of the white women older than 80 years. $^{4}$

The comparison reveals very similar pattern of the agewise trend with AMD prevalence in our study too with rise of the prevalence as the age increases though the study number was lower to determine exact prevalence rate when compared with other studies.

AMD were observed to be more prevalent in female gender $(7 \%)$ in our study with female: male ratio of 2.5:1 (OR 1.122). In the Beaver Dam Eye Study, women 75 years or older had seven times the incidence of late AMD as compared to men. ${ }^{6}$ Prevalence of late AMD in men was 1.1 percent in Funagata study in Japan and $0.3 \%$ in women. Though various AMD reports show different results regarding prevalence differences in male and female gender, majority reveals slight higher rates among females. ${ }^{1-2}$ The female gender prevalence of AMD finding was similar in our study with higher number AMD in females with increasing age. Role of hormones, estrogen deficiency have been implicated for this gender prevalence in women but the results are inconsistent in different studies. ${ }^{1,6}$ The other reasons could be due to long life expectancy and obesity in females. However, in Asian population study done in Japan and China higher prevalence was seen in male population. ${ }^{16}$

$95 \%$ of AMD in our study was atrophic form and $5 \%$ exudative form. In a study by Jennifer, prevalence rate for atrophic form was found to be $85 \%$ in people with age related macular degeneration. End stage age related macular degeneration was found in about $1.7 \%$ of all people aged over 50, and incidence rising with age $(0.7-1.4 \%$ in people aged $65-75,11.0-18.5 \%$ in people

Table 5. Risk factors and Odds ratio in AMD

\begin{tabular}{|c|c|c|c|c|}
\hline \multirow{2}{*}{ Risk factors } & \multicolumn{2}{|c|}{ Odds ratio (OR) } & \multirow{2}{*}{$\begin{array}{l}\text { 95\% Confidence interval } \\
\text { (Lower; Upper) }\end{array}$} & \multirow{2}{*}{ p Value } \\
\hline & Unadjusted & Adjusted & & \\
\hline Age $>71: \leq 70$ years & 8.011 & 2.221 & $0.041 ; 0.290$ & 0.00 \\
\hline Female: Male & 2.524 & 1.122 & $0.098 ; 1.081$ & 0.067 \\
\hline Hypertensive: Non- hypertensive & 0.300 & 0.928 & $0.694 ; 9.217$ & 0.160 \\
\hline Diabetes: Non- diabetics & 0.188 & 1.621 & $0.627 ; 40.866$ & 0.128 \\
\hline Smokers: Non-smokers & 1.157 & 0.494 & $0.199 ; 1.874$ & 0.388 \\
\hline Alcohol intake: Non-alcoholics & 0.751 & 0.274 & $0.233 ; 2.483$ & 0.650 \\
\hline Non-vegetarian: Vegetarian & 1.632 & 0.045 & $0.262 ; 3.486$ & 0.943 \\
\hline
\end{tabular}


aged over 85). The age-wise trend of exudative AMD in our study could not be compared with other studies because there were only two wet AMD cases. In our study, the visual impairment due to AMD was found to be $52.5 \%$ and $15 \%$ were blind. In US, AMD accounts for $13 \%$ legal blindness. ${ }^{4}$

Aging showed statistically significant increased risk for AMD $(p=0.00)$ in our study. Female gender and diabetes were also observed as increased risk for AMD though they were statistically insignificant $(p=>0.01)$. Alcohol intake, hypertension, smoking, and nonvegetarian status revealed no risk for AMD in our study $(p=>0.01)$. However, in other preexisting studies ${ }^{1,6,8,17}$ statistically significant increased risk for AMD was found with increasing age, in female gender, hypertension, diabetes, alcohol users and smokers. Howsoever, in some studies, risk factors like diabetes, hypertension and alcohol use were found to be statistically insignificant association for the development of AMD. Our findings in this study regarding risk factors could be due to small study group or might be due to missing out of risk factors as we depended solely on history to rule out presence of those risk factors.

Further study with large scale population is required in Nepal to confirm the exact incidence rate, prevalence rate, distribution age- wise, distribution sex-wise and risk factors for AMD.

\section{CONCLUSIONS}

The prevalence of AMD is $5 \%$ with female preponderance in ratio of 2.5:1. The increasing age showed statistically significant increased risk for its development. Female gender and diabetes were also observed as increased risk for it though they were statistically insignificant. Further studies are needed in large scale population to confirm the incidence rate, prevalence rate and associated risk factors in our population precisely.

\section{ACKNOWLEDGEMENTS}

We acknowledge Mr Umesh Aryal, Anju Shrestha, from Kathmandu Medical College Teaching Hospital for their help during the study period.

\section{REFERENCES}

1. Friedman DS, O'Colmain BJ, Muñoz B, Tomany SC, McCarty $\mathrm{C}$, de Jong PT, et al. Prevalence of age-related macular degeneration in the United States. Arch Ophthalmol. 2004 Apr;122(4):564-72.

2. Fraser-Bell S, Wu J, Klein R, Azen SP, Varma R. Smoking, alcohol intake, estrogen use, and age-related macular degeneration in Latinos: the Los Angeles Latino Eye Study. Am J Ophthalmol. 2006 Jan;141(1):79-87.

3. West SK, Rosenthal FS, Bressler NM, Bressler SB, Munoz B, Fine SL, Taylor HR. Exposure to sunlight and other risk factors for age-related macular degeneration. Arch Ophthalmol. 1989 Jun;107(6):875-9.

4. Michael BG. A Clinician's View of the Molecular Genetics of Age-Related Maculopathy. Arch Ophthalmol 2007;125:21-9.

5. Seddon JM, Ajani UA, Sperduto RD. Dietary carotenoids, vitamins $\mathrm{A}, \mathrm{C}$, and $\mathrm{E}$, and advanced age-related macular degeneration: Eye Disease Case-Control Study Group. JAMA 1994;272:1413-20.

6. Klein R, Klein BE, Linton KL. Prevalence of age-related maculopathy. The Beaver Dam Eye Study. Ophthalmology. 1992 Jun;99(6):933-43.

7. Smith W, Mitchell P, Wang JJ. Gender, oestrogen, hormone replacement and age-related macular degeneration: results from the Blue Mountains Eye Study. Aust N Z J Ophthalmol. 1997;25(suppl 1):S13-S15.

8. Seddon JM, Cote J, Rosner B. Progression of age-related macular degeneration: association with dietary fat, transunsaturated fat, nuts, and fish intake. Arch Ophthalmol. 2003 Dec;121(12):1728-37.
9. Mitchel P, Smith W, Altebo K. Prevalence of age-related maculopathy in Australia: The Blue Mountain Study: Ophthalmol 1995;102:1450-60.

10. Vingerling JR, Diclemans I, Hofman A. The prevalence of agerelated maculopathy in the Rotherdam Study. Ophthalmol 1995;102:205-10.

11. Narendran V, Tulsiraj RD, Kim R. The prevelance of age-related maculopathy in South India. Investigative Ophthalmology and Visual Science 2000;41:119-22.

12. Gregor Z, Joffe L. Senile macular changes in the black African. Br J Ophthalmol. 1978 Aug;62(8):547-50.

13. Jain IS, Prasad P, Gupta A. Senile macular degeneration in India. Ind J Ophthalmol 1984;32: 343-6.

14. Wu ZQ. Epidemiologic survey of senile macular degeneration. Chung Hua Yen Ko Tsa Chih 1992;28:246-7.

15. Kawasaki R, Wang JJ, Ji GJ, Taylor B, Oizumi T, Daimon M, et al. Prevalence and risk factors for age-related macular degeneration in an adult Japanese population: the Funagata study. Ophthalmology. 2008 Aug;115(8):1376-81.

16. Shih-Jen C, Ching-Yu C, Kai-Ling P, An-Fei L, Wen-Ming H, Jorn-Hon L, et al. Prevalence and associated risk Factors of Age-Related Macular Degeneration in an Elderly Chinese Population in Taiwan: The Shihpai Eye Study. Invest Ophthalmol Vis Sci. 2008;49:3126-33.

17. Metelitsina TI, Grunwald JE, DuPont JC, Ying GS. Effect of systemic hypertension on foveolar choroidal blood flow in age related macular degeneration. Br J Ophthalmol. 2006 Mar;90(3):342-6. 